\title{
COMUNICAÇÃO COMO INSTRUMENTO DA INDÚSTRIA CRIATIVA: UMA ANÁLISE DA ACB - ASSOCIAÇÃO CULTURAL DE BOSSOROCA (RS)
}

\author{
Priscila Bicca Urach ${ }^{1}$
}

RESUMO: Este trabalho possui o objetivo de refletir sobre a relação entre comunicação e indústrias criativas a partir da análise da $\mathrm{ACB}$ - Associação Cultural de Bossoroca, localizada em Bossoroca- RS, e mapear as ferramentas de comunicação utilizadas para a divulgação de seus trabalhos. Finalizando com uma análise da indústria criativa - em que, através da exploração de conhecimento e criatividade, gera riqueza e empregos, adotando a comunicação em seus processos e práticas.

Palavras-chave: comunicação; indústria criativa; ACB.

ABSTRACT: This work aims to reflect on the relationship between communication and creative industries from the analysis of the ACB - Associação Cultural de Bossoroca, located in Bossoroca - RS, and to map the communication tools used for the dissemination of their work. Ending with an analysis of the creative industry in which, through the exploration of knowledge and creativity, it generates wealth and jobs, adopting communication in its processes and practices.

Keywords: communication; creative industry; CBA

\section{INTRODUÇÃO}

Percebemos a possibilidade de análise científica acadêmica em relação às estratégias comunicacionais empreendidas na Indústria Criativa, que aproxime campos do saber, como a cultura e comunicação. Esta pesquisa incide na relação entre teoria e prática no âmbito da comunicação na contemporaneidade, considerando a comunicação integradora ou integrada, como no caso da Indústria Criativa. Como

\footnotetext{
I Discente do Programa de Pós-Graduação em Comunicação e Indústria Criativa. Universidade Federal do Pampa - Campus São Borja - RS.priscilaurach.aluno@unipampa.edu.br.
} 
dizem Polistchuck e Trinta (2003, p. 18), "O ato teórico plano se realiza em referência a uma prática, e toda prática bem-sucedida evidencia uma teoria a ela subjacente.

Feitosa, S. A.; Belochio, V. C. (2018) abordam sobre Comunicação e Indústria Criativa como o domínio do "saber-fazer" e do "saber sobre o fazer". Referente ao primeiro, ao visarmos uma estratégia comunicacional de produção - um site, por exemplo -, consideramos um perfil de público-alvo, que nos guia para a produção mais apropriada de textos, imagens e layout. Tudo é pensado de forma criativa, dialogando com a faixa etária desse público, usando uma linguagem adequada e voltada para ele, que pode ou não surtir o efeito esperado. É uma prática que representa um exemplo do conhecimento do tipo "saber fazer". Já sobre o "saber sobre o fazer", podemos considerar que está relacionado com o conhecimento acerca de como desenvolver cada etapa do processo ou produto. Ou seja, nos torna cientes de que, além da busca por conceitos metodológicos, precisamos saber como proceder com a construção de um site e como "manusear" a linguagem de modo que alcance seu público.

Sendo assim, é fundamental a percepção e a análise das mudanças no campo da comunicação, que vão muito além da migração do analógico para o digital. Já dizia McLuhan (1975): o meio não é um simples canal de passagem do conteúdo, um simples veículo de transmissão da mensagem. O meio é um elemento determinante da comunicação. Conforme o autor, isso significa que os meios são extensões dos sentidos dos homens, funcionando como uma espécie de prótese - assim, seguindo essa lógica, smartphones ou qualquer outro dispositivo convergente podem ser extensões dos dedos ou das mãos, e mais, uma extensão da mente de cada um de nós, configurando uma relação simbiótica entre tecnologia e homem (MCLUHAN, 1975, p.21).

Dessa forma, entendemos que não está mais somente nas mãos da mídia tradicional produzir e publicar informações; está em cena a mídia propagável, ou seja, 
a cultura da conexão, que examina um modelo híbrido e emergente de circulação, segundo o qual as pessoas comuns podem decidir o que consomem e o que compartilham - através de mídias sociais e aplicativos. Para Jenkins, H.; Green, J.; Ford, S. (2014), quando pensamos em transmitir, precisamos saber sobre o conteúdo intangível que nos cerca na Web 2.0, precisamos entender a produção e a circulação do conteúdo, para que ele se espalhe e seja considerado relevante.

Vamos retomar as questões próprias da Indústria Criativa (IC): ela surgiu nos anos 90, segundo Jambeiro e Ferreira (2012), como tentativa de agregar setores que tinham em comum a criatividade como principal elemento produtivo. Assim, entende-se que a atividade do setor criativo é a IC, sendo caracterizada como tal por possuir como insumo básico a criatividade e a geração de direitos autorais. Para a Conferência das Nações Unidas sobre Comércio e Desenvolvimento (UNCTAD, 2012, p. 7), a ideia de Indústria Criativa envolve a ampliação do conceito de “criatividade”, "passando-o de atividades que possuem um sólido componente artístico para 'qualquer atividade econômica que produza produtos simbólicos intensamente dependentes da propriedade intelectual, visando o maior mercado possível' (UNCTAD, 2004)”. Assim (UNCTAD, 2012, p. 7), a criatividade deixa de se restringir a "atividades upstream (culturais tradicionais, tais como artes cênicas ou visuais)", para também incluir "atividades downstream (que possuem uma proximidade muito maior com o mercado, como publicidade, editoras ou atividades relacionadas à mídia)”.

Os elementos estratégicos e instrumentais - como o jornalismo cultural, as relações públicas em instituições culturais, dentre outros -, e os setores criativos e culturais - como a publicidade, as mídias digitais, o audiovisual, dentre outros -, estão ligados à comunicação, pois essa é posta como constituinte deles. É a partir dessa percepção, considerando as implicações e concepções teóricas e práticas do campo como e para a IC, que se nota a necessidade de refletir sobre a comunicação e a suas estratégias no âmbito da Indústria Criativa. 
O objeto e o recorte da presente investigação estão direcionados ao trabalho da Associação Cultural de Bossoroca - RS. Partindo do cenário em que o setor criativo e cultural tem sido visto como alvo estratégico das políticas públicas de desenvolvimento dos territórios, por sua capacidade de gerar empregos e valorizar a diversidade cultural (Augusto Mateus \& Associados, 2010), busca-se verificar como a comunicação pode ser estrategicamente integradora ou integrada à $I C$, através dos diferentes setores criativos e culturais da ACB, e analisar as estratégias comunicacionais usadas por essa entidade.

\section{Como surgiu a Associação Cultural de Bossoroca - ACB}

Bossoroca (RS) possui peculiaridades oriundas do entrelaçamento de signos e representações simbólicas advindas da relação entre atividades culturais criativas e turismo. O município está localizado na região das Missões, a Noroeste do Estado do Rio Grande do Sul, e hoje tem uma população de pouco mais de seis mil habitantes. Por um lado, é marcado por sua tranquilidade, considerado um local seguro e agradável para se viver; e, por outro, se destaca por uma movimentação no âmbito cultural, através de ações que envolvem a comunidade e chamam a atenção dos municípios vizinhos e dos visitantes. Nessa pesquisa destaca-se, de modo particular, o trabalho realizado na cidade pela Associação Cultural de Bossoroca (ACB) - RS.

Em 1994, um grupo de doze cidadãos bossoroquenses criou a ACB. Trata-se de uma entidade civil sem fins lucrativos, que tem como objetivos principais a integração dos segmentos da comunidade, por meio de manifestações culturais. A ACB promove estudos e divulga diferentes expressões artísticas, através de vários tipos de eventos e promoções. Possui como foco a cultura das diversas regiões do estado e do país e, dessa forma, estimula a transformação da comunidade em um centro de integração e desenvolvimento cultural. Seus projetos recebem o apoio financeiro de pessoas físicas e jurídicas. Também têm vinculação ao financiamento para atividades culturais viabilizado pela LIC - Lei de Incentivo à Cultura. 
Os principais projetos desenvolvidos pela $\mathrm{ACB}$ são:Quadro I: Projetos da Associação Cultural de Bossoroca (Fonte: ACB, 2021)

\begin{tabular}{|c|c|}
\hline MANANCIAL MISSIONEIRO DA CANÇÃO & $\begin{array}{l}\text { Festival nativista/missioneiro, iniciado em } \\
\text { I99o, no qual podem ser inscritas músicas } \\
\text { inéditas referentes a temas sobre Bossoroca. } \\
\text { Posteriormente é gravado um CD com as } \\
\text { músicas vencedoras e mais populares. }\end{array}$ \\
\hline $\begin{array}{lll}\text { ENCONTRO } & \text { SUL-AMERICANO } & \text { DE } \\
\text { FOLCLORE } & & \end{array}$ & $\begin{array}{l}\text { Inserido nas comemorações da Semana } \\
\text { Municipal do Folclore, é um dos mais } \\
\text { significativos eventos da região, promovendo a } \\
\text { integração do Brasil com Argentina, Uruguai, } \\
\text { Paraguai e Chile. }\end{array}$ \\
\hline $\begin{array}{l}\text { BOSSOROCA - UM CANTOCHÃO } \\
\text { MISSIONEIRO }\end{array}$ & $\begin{array}{l}\text { Edição de um CD com participação exclusiva } \\
\text { de músicos, poetas e compositores naturais de } \\
\text { Bossoroca. O objetivo é valorizar e divulgar o } \\
\text { trabalho de artistas locais. }\end{array}$ \\
\hline PROJETO MEMÓRIA FARROUPILHA & $\begin{array}{l}\text { Com a primeira edição em } 2012 \text { e o apoio da } \\
\text { Eletrosul, esse projeto visa transmitir, através } \\
\text { de palestras e, principalmente voltado aos mais } \\
\text { jovens, o verdadeiro sentido do tradicionalismo, } \\
\text { mostrando essa história de uma forma mais } \\
\text { real, com a devida preocupação com os aspectos } \\
\text { tradicionais da cultura gaúcha e missioneira. }\end{array}$ \\
\hline 2I - OS ANOS QUE NÃO FORAM ESCRITOS & $\begin{array}{l}\text { Documentário em vídeo, com depoimento de } \\
\text { pessoas da região, sobre o período do regime } \\
\text { militar, de } 1964 \text { a } 1985 \text {, tendo por objetivo } \\
\text { principal levar esse conteúdo a alunos e } \\
\text { professores dos níveis de ensino Fundamental e } \\
\text { Médio. }\end{array}$ \\
\hline $\begin{array}{l}\text { NOSSOS VALORES - POETAS EM PROSA E } \\
\text { VERSO }\end{array}$ & $\begin{array}{l}\text { Coletânea de trabalhos em livro - contos, } \\
\text { poemas, crônicas e relatos de pessoas nascidas } \\
\text { na Bossoroca e também daqueles que lá se } \\
\text { aquerenciaram. }\end{array}$ \\
\hline BOSSOROCA EM CANTO E DANÇA & $\begin{array}{l}\text { Projeto realizado em parceria com o Governo } \\
\text { Municipal, através da Secretaria Municipal de } \\
\text { Assistência Social e CRAS, cuja finalidade é } \\
\text { mostrar o trabalho desenvolvido com jovens e } \\
\text { crianças das escolas locais em aulas de canto e } \\
\text { dança de forma livre. }\end{array}$ \\
\hline
\end{tabular}




\section{RESULTADOS E DISCUSSÕES}

Para situar nosso objeto dentro da Linha de Pesquisa como IC, devemos pensar a constituição do objeto de conhecimento da comunicação ou a comunicação como processo ou produto auxiliar, visando dois horizontes: "ou a comunicação é o objeto ou é auxiliar a outra área do conhecimento" (FEIL e GUINDANI, 2018, p.84). No que tange a $\mathrm{ACB}$, a comunicação é o objeto, conforme nos permitem interpretar Feil e Guindani (2018), uma vez que as ações desenvolvidas pela Associação ocorrem quando há um 'cliente' - não entendido necessariamente no sentido mercadológico, mas no sentido de ser pessoa/instituição beneficiada pelo processo ou produto.

Portanto, foi observada a relação existente entre a $\mathrm{ACB}$ e os tipos de comunicação adotados por ela, incluindo os produtos comunicacionais de que se utiliza para a divulgação de seu trabalho e o relacionamento com seu público. Nas buscas encontramos um blog, uma página do Facebook e dois websites:

Quadro 2: Canais de comunicação da Associação Cultural de Bossoroca

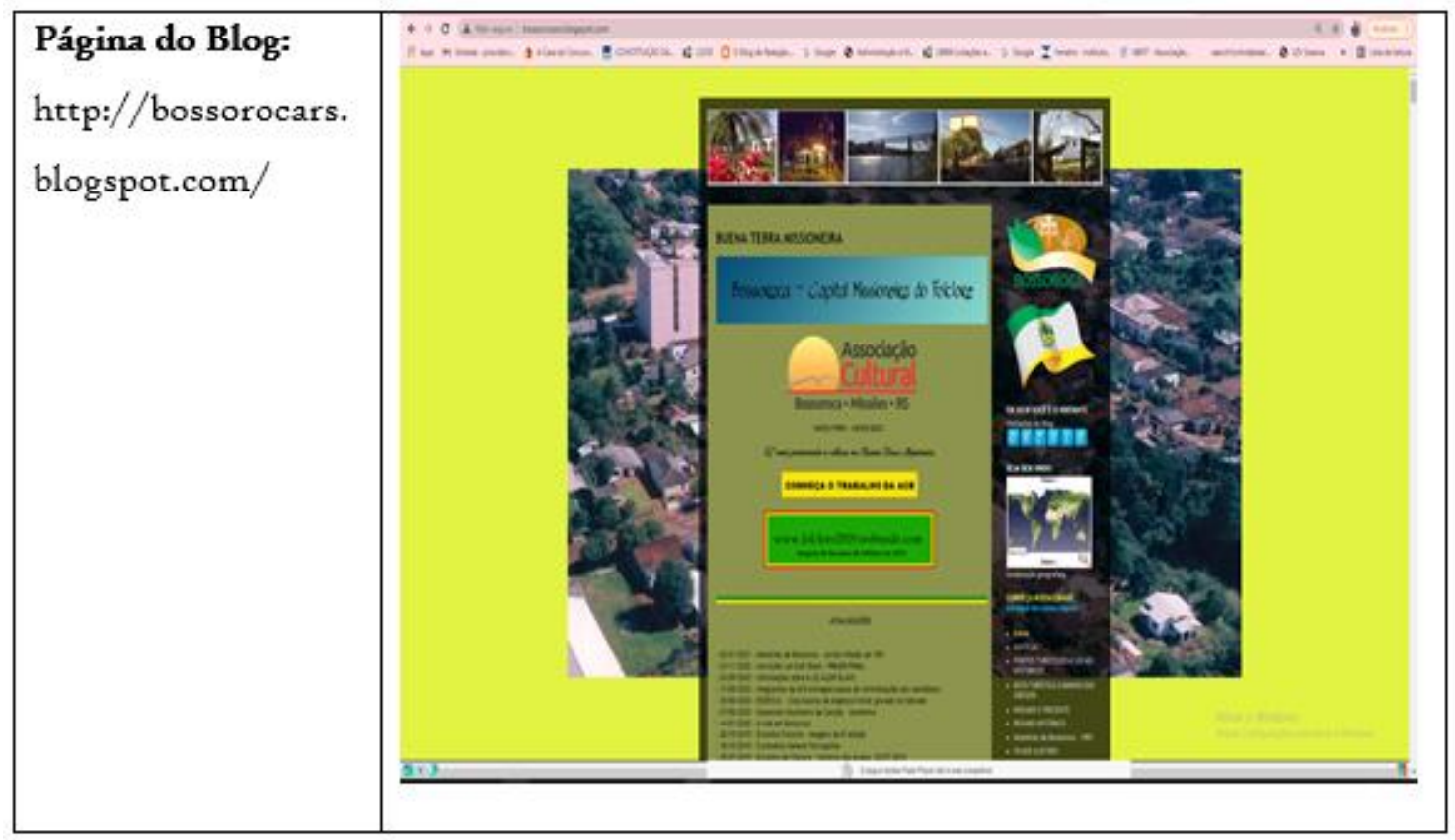



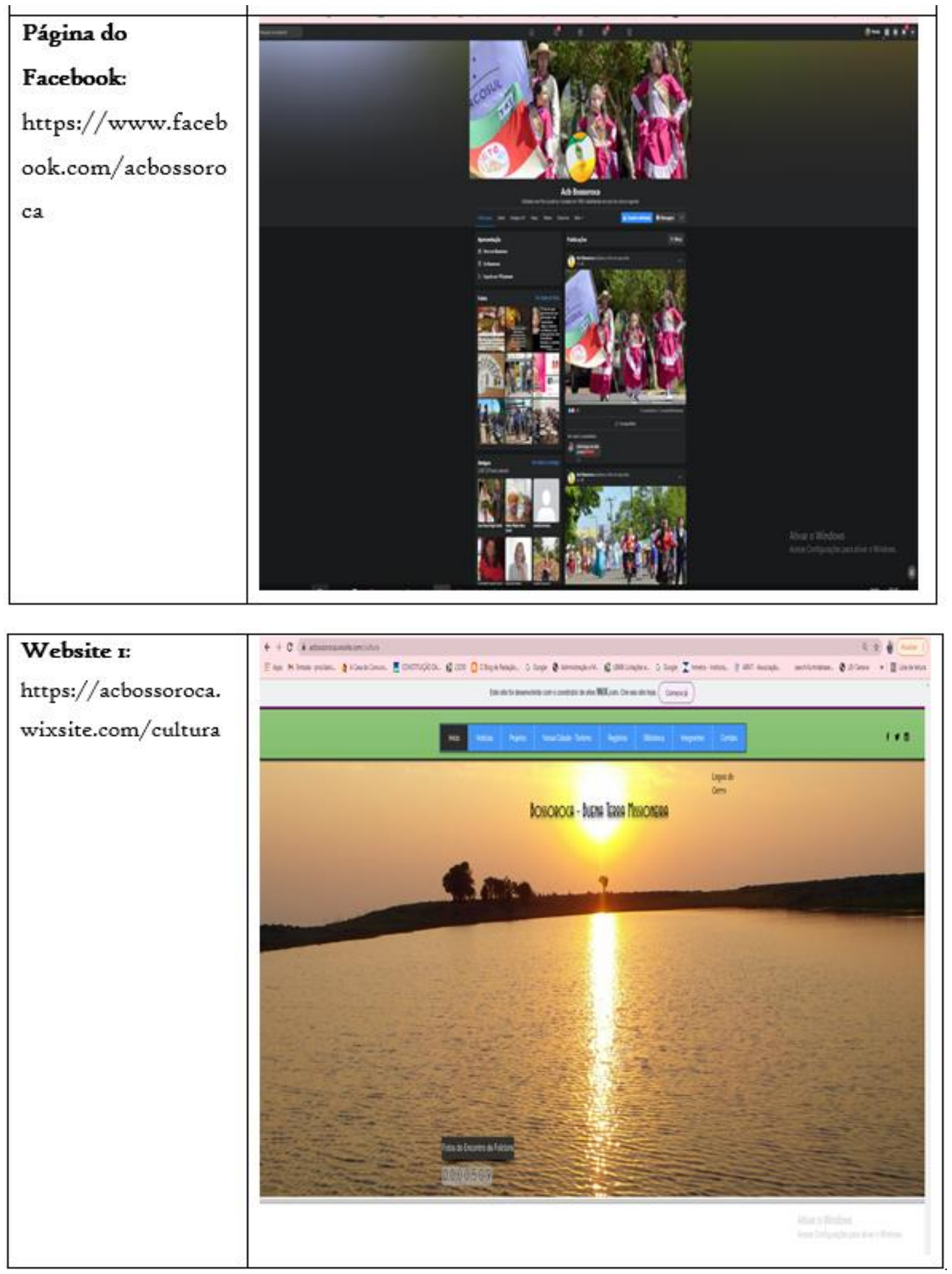


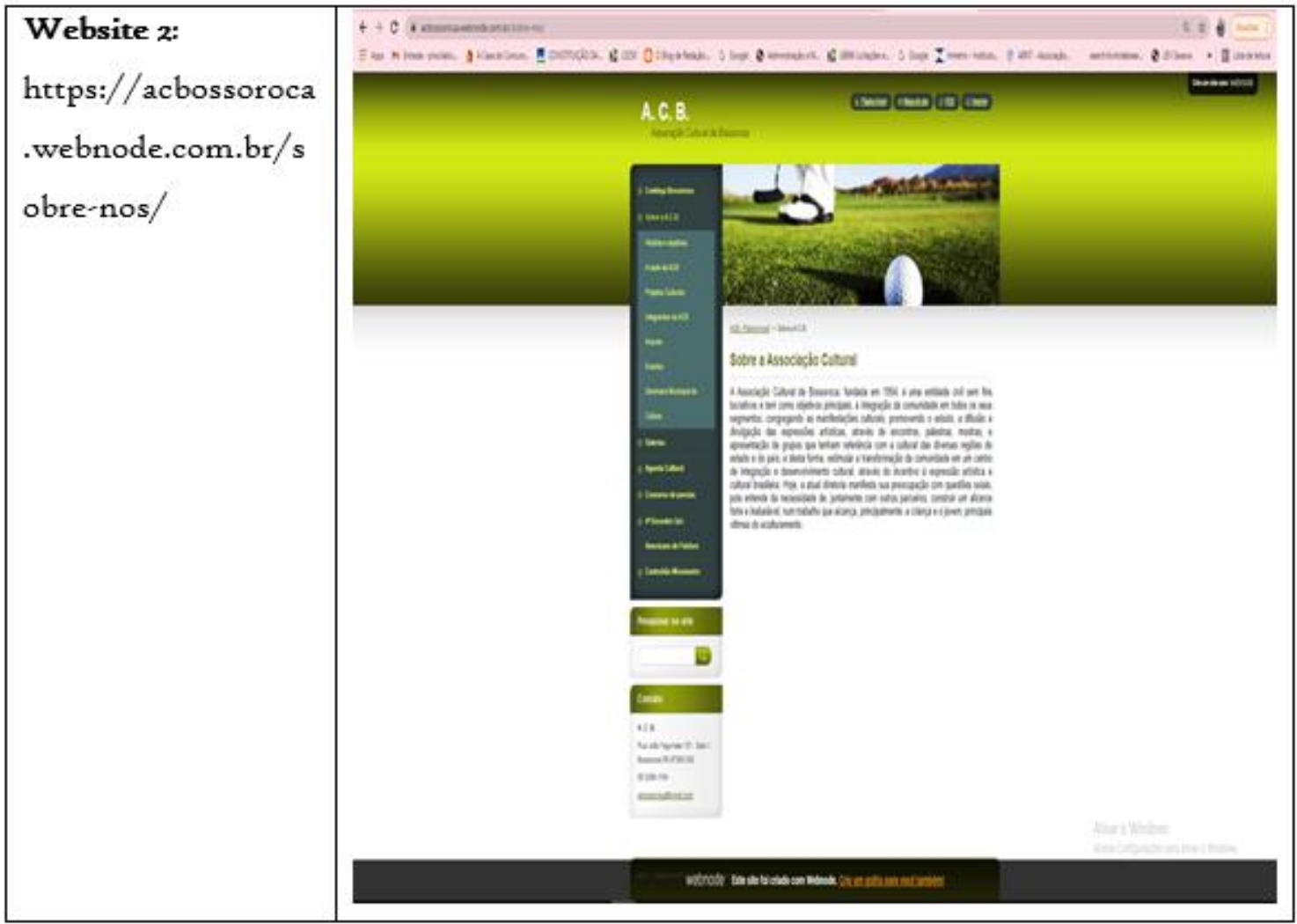

Fonte: Pesquisa da autora, internet, 2021

Para nossa investigação, servimo-nos dos conhecimentos de Muniz Sodré (2006) quanto à noção de "estratégia” na comunicação. Entendemos estratégia como algo entre a condição cognitiva e sua realização, decorrente de um processo racional de escolhas orientadas por condições determinadas pelo contexto. Sabemos, pois, que essas escolhas são flexíveis e adaptáveis às circunstâncias em que se realizam. Também julgamos importante contextualizar "comunicação", nos apropriando da teoria de Iasbeck (2010), para o qual comunicação não é privilégio dos humanos, mas é entre esses que ela se torna objeto maior de ocupações e preocupações.

Comunicação é um processo, algo que se dá no tempo e que, portanto, tem início e desenvolvimento, encerrandose como um ciclo. Porém, não se extingue enquanto processo: ela continua abastecida e reabastecida por 
respostas, retornos, feedbacks e reações. (IASBECK, 2оı, p.I6)

Observamos que a ACB utiliza ferramentas comunicacionais importantes e conhecidas para a divulgação de seus trabalhos. Através delas mostra também sua história e trajetória, incluindo seus projetos.

No entanto, ao analisarmos as ferramentas, notamos algumas questões a considerar. Começando pelo Facebook: o post mais visualizado possui 7r curtidas, sendo referente ao Encontro Sul-americano de Folclore, visto como o projeto mais popular. Percebemos que esse tipo de divulgação não tem uma atenção permanente da equipe, pois não se vê uma atualização frequente. A divulgação maior acontece após o evento, segundo o número de postagens. Outro ponto observado foi que a página é livre para artistas divulgarem seus trabalhos, "marcando" a ACB e, consequentemente, aparecendo seu conteúdo na timeline. Consideramos que isso pode tirar um pouco do foco o objetivo principal, que é a própria ACB.

Quanto aos websites, ambos trazem um pouco da história da Associação, principais atividades, fotos e equipe, porém, essa duplicidade de endereços pode gerar confusão diante do público - afinal, são da mesma associação cultural? Qual deles acessar? Os dois websites também não são atualizados frequentemente, sendo a última notícia publicada em 2019. No entanto, ali é possível realizar contato através de e-mail, o que seria algo positivo. Já o blog é a única ferramenta que menciona a existência de outra ferramenta utilizada, por meio de link (que remete a apenas um dos sites). No blog também há informações sobre a ACB e um vasto material sobre artistas locais e sobre Bossoroca - embora, igualmente, não seja atualizado com frequência.

\section{CONCLUSÕES}

Em um primeiro momento percebe-se as quatro ferramentas comunicacionais mencionadas não são exploradas a contento, sobretudo quanto a estratégias de 
publicação e periodicidade de atualização. Consequentemente, isso não contribui para reforçar a imagem da ACB como um grupo consolidado dentro da cidade. Tal situação, por sua vez, se reflete em uma participação da comunidade aquém do desejado, mesmo em eventos de grande expressividade artística-cultural, como o Encontro Sul-americano de Folclore. Com mais publicações, fomento e divulgação, o grupo se tornaria mais conhecido e seus projetos ganhariam incremento em público e notoriedade.

Com o uso mais consciente e estratégico da comunicação, Bossoroca, através da $\mathrm{ACB}$, poderá se tornar uma referência em termos de folclore e atrair espectadores de dentro e de fora do país, do estado e da cidade. Isso, potencialmente, geraria ganhos para o turismo e o comércio local, além da possibilidade de geração de renda a pequenos empreendedores e artistas locais - por exemplo, com incentivo à participação de artesões nos eventos.

Nossa análise nos permitiu examinar as relações socioeconômicas de modo relacional, desde as interfaces, conjugações, até os cruzamentos das especificidades de cada campo, através da comunicação e da Indústria Criativa. Com isso, verificamos que esses elementos não estão distantes uns dos outros: eles se complementam. Dessa forma, conseguimos analisar a Indústria Criativa como objeto de reflexão para a comunicação. Em síntese, constatamos o valor do papel da comunicação como suporte para os setores da economia criativa, como para suas promoções - utilizandose de práticas, produtos e estratégias, criados pelos segmentos geradores de produtos e processos criativos inerentes à Indústria Criativa. A articulação dos conhecimentos oriundos do jornalismo e demais segmentos da Comunicação Social, em prol de uma comunicação criativa e estratégica, tem chances de contribuir para o desenvolvimento e para uma melhor inserção de entidades, como a $\mathrm{ACB}$, junto ao seu público de destino. 


\section{REFERÊNCIAS}

AUGUSTO MATEUS \& ASSOCIADOS. O sector cultural e criativo em Portugal. Lisboa: Estudo para o Ministério da Cultura. Relatório Final, 2010.

FEIL,S.G; GUINDANI, J.F. Comunicação como e comunicação para a Indústria Criativa. In: GUINDANI, J. F.; E SILVA, M. G (orgs.). Comunicação e Indústria Criativa: políticas, teorias e estratégias. Jaguarão (RS):CLAEC, 2018. p. 8I-9o.

FEITOSA, S. A.; BELOCHIO, V. C. Quatro relações entre Comunicação e Indústria Criativa. In: Marcela Guimarães e Silva; Joel Felipe Guindani. (Org.). Comunicação e Indústria Criativa: políticas, teorias e estratégias. Ied. Jaguarão: CLAEC, 2018, p. 59-79.

IASBECK, Luiz Carlos Assis. Ouvidoria é comunicação. (artigo). In: Revista USP. v. 7 n. 12 (2010): Ouvidoria e Comunicação. Disponível em:< https://www.revistas.usp.br/organicom/article/view/139045>. Acesso em: o4 de junho de 2021

JAMBEIRO, Othon; FERREIRA, Fábio. Compreendendo as Indústrias Criativas de Mídia: contribuições da economia política da comunicação. Revista Comunicação Midiática, v.7, n.3, p.178-194, set./dez. 2012.

JENKINS, H.; GREEN, J.; FORD, S. Onde a web 2.0 deu errado. In:

Cultura da conexão: criando valor e significado por meio da mídia propagável. São Paulo: leph, 2014. P. 77-II8.

MCLUHAN, M. O meio é a mensagem. In: Os meios de comunicação como extensão do homem (understanding media). São Paulo: Cultrix, 1975. P. 21- 37.

SODRÉ, Muniz. Antropológica do Espelho: uma teoria da comunicação linear em rede. Petrópolis, RJ: Vozes, 2002.

POLISTCHUK, Ilana; Trinta; Aluizio Ramos. (2003). Teorias da Comunicação: o pensamento e a prática da Comunicação Social. 5. ed. Rio de Janeiro: Elsevier.

RELATÓRIO de economia criativa 2010 - economia criativa uma opção de desenvolvimento. Brasília: Secretaria da Economia Criativa/Minc.; São Paulo: Itaú Cultural, 2012. 